\title{
Algunos parámetros para la incorporación de los estándares del sistema interamericano de protección de los derechos humanos en la tutela constitucional, legal y judicial del derecho a un ambiente sano en Panamá
}

\author{
Alguns parâmetros para a incorporação dos padrões do \\ sistema interamericano de proteção dos direitos humanos \\ na tutela constitucional, legal e judicial do direito a um \\ ambiente saudável no Panamá
}

\section{Félix Wing Solís}

Licenciado en Derecho y Ciencias Políticas por la Universidad de Panamá, Magíster en Estudios Legales Internacionales por American University, Washington, DC, EE. UU., asistente de magistrado de la Sala Tercera de lo Contencioso-Administrativo y Laboral de la Corte Suprema de Justicia de Panamá, profesor de Derecho Internacional Público, Derecho Comparado, Derechos Humanos (DDHH) y Derecho Ambiental de la Universidad Latina de Panamá, Ciudad de Panamá - Panamá, e-mail: fwings@fulbrightmail.org

\section{Resumen}

Durante décadas, las normas internacionales de Derecho Ambiental y Derechos Humanos $(\mathrm{DDHH})$ han evolucionado en paralelo. Sin embargo, el impacto cada vez más evidente 
de daños ambientales en la dignidad de las personas se ha convertido imperativo para una mayor interacción entre los dos ramos del Derecho. Este trabajo es una propuesta viable para esa interacción en el contexto de Panamá. Examinando la evolución de los dos regímenes de protección en Panamá, vamos a intentar ofrecer algunos parámetros doctrinarios y una política jurisprudencial, que pueden servir como agentes de los tres órganos del Estado para el adecuado incorporar en sus deliberaciones y decisiones, las normas del Sistema Interamericano de Derechos Humanos en la defensa del derecho a un ambiente saludable.

Palabras clave: Medio ambiente. Derechos humanos. Panamá.

\section{Resumo}

Durante décadas, as normas internacionais de Direito Ambiental e Direitos Humanos (DH) têm evoluído em paralelo. No entanto, o impacto cada vez mais evidente de danos ambientais sobre a dignidade das pessoas se tornou imperativo para uma maior interação entre os dois ramos do Direito. Este trabalho é uma proposta viável para essa interação no contexto do Panamá. Examinando a evolução dos dois regimes de proteção no Panamá, vamos tentar oferecer alguns parâmetros doutrinários e uma política jurisprudencial que podem servir como agentes dos três órgãos do Estado para incorporar adequadamente, em suas deliberações e decisões, as normas do Sistema Interamericano de Direitos Humanos na defesa do direito a um ambiente saudável.

Palavras-chave: Meio ambiente. Direitos humanos. Panamá.

\section{Introducción}

Durante décadas, los estándares internacionales de Derecho Ambiental y de Derechos Humanos (DDHH) han evolucionado en forma paralela (ORELLANA, 2008, p. 291). No obstante, la cada vez más evidente incidencia del daño ambiental sobre la dignidad de las perso- 
nas ha hecho imperativa una mayor interacción entre ambas ramas del Derecho. ${ }^{1}$

Este trabajo pretende ser una propuesta para viabilizar esta interacción en el contexto panameño. Examinando la evolución de ambos regímenes de protección en Panamá, intentaremos ofrecer algunos parámetros doctrinales, normativos y jurisprudenciales que puedan servir a los operadores de los tres órganos del Estado para incorporar adecuadamente, en sus actuaciones y decisiones, los estándares interamericanos de DDHH en la tutela del derecho a un ambiente sano.

\section{Los derechos o intereses difusos desde la perspectiva del derecho internacional de los derechos humanos (DDHH)}

\section{Naturaleza jurídica de los derechos o intereses difusos}

Para llevar a cabo un análisis integral de cualquier régimen de protección de los derechos o intereses difusos, como lo es el Derecho Ambiental panameño, el punto de partida de dicho análisis debe estar ubicado en la teoría de los $\mathrm{DDHH},{ }^{2}$ más que en la teoría constitucional o administrativa. ${ }^{3}$ Ello es así por cuanto la tutela de los DDHH es un

1 Vid. CENTRO DE DERECHOS HUMANOS Y MEDIO AMBIENTE (CEDHA). Informe sobre Derechos Humanos y Medio Ambiente en América, elaborado por Sofía Bordenave con la colaboración de Romina Picolotti, Córdoba, 2002. Presentado en la audiencia de carácter general sobre Derechos Humanos y Ambiente de la Comisión Interamericana de Derechos Humanos (CIDH), Washington, 16 oct. 2002.

2 Expusimos este criterio por primera vez en Félix Wing Solís (2002, p. 68).

3 Cf. PANAMÁ. AUTORIDAD NACIONAL DEL AMBIENTE (ANAM), AGENCIA DE LOS ESTADOS UNIDOS PARA EL DESARROLLO INTERNACIONAL (USAID, por sus siglas en inglés) \& ACADEMIA PARA EL DESARROLLO EDUCATIVO (AED, por sus siglas en inglés). Curso de Derecho Ambiental Administrativo para Funcionarios de la Autoridad Nacional del Ambiente (ANAM) y las Unidades Ambientales Sectoriales (UAS), Proyecto Piloto de Gobernabilidad y Justicia Ambiental, Félix Wing Solís \& Víctor L. Benavides P., Consultores, Panamá, sep./nov. 2005, p. 34 (en adelante, Curso de Derecho Ambiental). 
tema transversal a todo el ordenamiento jurídico, y en particular a las mencionadas ramas del Derecho Público. Como veremos a lo largo del presente trabajo, la naturaleza jurídica de los derechos o intereses difusos se encuentra inserta de un modo muy particular dentro del marco de los DDHH.

Para facilitar el estudio y la enseñanza de los DDHH, éstos han sido divididos por la doctrina mayoritaria en tres generaciones (Cuadro 1). ${ }^{4} \mathrm{El}$ primer proponente de tal división, inspirada en los ideales de la Revolución Francesa (Liberté, égalité, fraternité), fue el jurista francés de origen checo Karel Vašák, ${ }^{5}$ en las postrimerías de su desempeño como primer Secretario General del Instituto Internacional de Derechos Humanos (IIDH), ${ }^{6}$ organización no gubernamental (ONG) con sede en Estrasburgo, Francia. ${ }^{7}$

Aun cuando no todos los expertos agrupan o categorizan a los DDHH de la misma manera, para los propósitos del presente trabajo los dividiremos en atención a cuatro criterios:

a) el orden en que surgieron históricamente;

4 Cf. INSTITUTO DE ESTUDIOS POLÍTICOS PARA AMÉRICA LATINA Y ÁFRICA - IEPALA. Curso Sistemático de Derechos Humanos (DDHH), Jesús Lima Torrado \& Fernando Rovetta, Coordinadores, Madrid, 1996, II.B.7.2. En relación a los sujetos titulares de los bienes de la personalidad.

5 Cf. VAŠÁK, Karel. "A 30-year struggle. The sustained efforts to give force of law to the Universal Declaration of Human Rights". París: Unesco, 1977, pp. 29-32. Cit. por VARIOS. Human Rights in the World Community. Issues and Actions. Richard Pierre Claude \& Burns H. Weston, eds., 2da ed., University of Pennsylvania Press, Philadelphia, 1992, p. 6, nota 10.

6 Cf. ORGANIZACIÓN DE LAS NACIONES UNIDAS - ONU. "Karel Vašák", Reaffirming Human Rights for All, $61^{\text {st }}$ Annual Non-Governmental Organization (NGO) Conference, Departamento de Información Pública (DPI), París, 3-5 sep. 2008.

7 El IIDH fue fundado por el ilustre jurista galo René Cassin, Premio Nóbel de la Paz 1968, quien fuera Juez de la Corte Europea de DDHH y uno de los principales inspiradores de la Declaración Universal de los DDHH (Cf. INSTITUT INTERNATIONAL DES DROITS DE L'HOMME - IIDH, L'Institut, cuyo sexagésimo aniversario fue celebrado por todo el mundo el 10 dic. 2008, Día Internacional de los DDHH, y en cuya redacción colaboró el también ilustre jurista panameño Ricardo J. Alfaro, quien fuera Juez de la Corte Internacional de Justicia (CIJ). (Cf. CAJAR PÁEZ, Aristides. "Ricardo J. Alfaro en la ONU", La Prensa, 15 oct. 2005). No debe confundirse con el Instituto Interamericano de Derechos Humanos, organización académica con sede en San José, Costa Rica, que utiliza las mismas siglas.

Revista de Direito Econômico e Socioambiental, Curitiba, v. 1, n. 1, p. 149-182, jan./jun. 2010 
b) el tipo de derechos subjetivos que comprenden;

c) los bienes de la personalidad tutelados;

d) los titulares de los derechos subjetivos o bienes de la personalidad. Para tales efectos, tomaremos como base el planteamiento teórico hecho por el Curso Sistemático de Derechos Humanos, publicado en 1996 por el Instituto de Estudios Políticos para América Latina y África (Iepala), ONG con sede en Madrid, España, que ha sido prohijado por nuestra Corte Suprema de Justicia (CSJ), ${ }^{8}$ y sobre el cual haremos algunas precisiones.

Cuadro 1 - Las tres generaciones de los DDHH

\begin{tabular}{llll}
\hline $\begin{array}{l}\text { Orden de } \\
\text { surgimiento } \\
\text { histórico }\end{array}$ & $\begin{array}{l}\text { Tipo de derechos } \\
\text { subjetivos }\end{array}$ & $\begin{array}{l}\text { Bienes de la } \\
\text { personalidad } \\
\text { tutelados }\end{array}$ & Titulares \\
\hline $\begin{array}{l}\text { Primera } \\
\text { generación }\end{array}$ & $\begin{array}{l}\text { Derechos o intereses } \\
\text { individuales }\end{array}$ & $\begin{array}{l}\text { Derechos civiles } \\
\text { y políticos o de la } \\
\text { libertad }\end{array}$ & Las personas \\
$\begin{array}{l}\text { Segunda } \\
\text { generación }\end{array}$ & $\begin{array}{l}\text { Derechos o intereses } \\
\text { colectivos }\end{array}$ & $\begin{array}{l}\text { Derechos económicos, } \\
\text { sociales y culturales } \\
\text { (Desc) o de la igualdad }\end{array}$ & $\begin{array}{l}\text { La colectividad } \\
\text { como un todo, o } \\
\text { bien aquellos grupos } \\
\text { de personas cuyos } \\
\text { miembros comparten } \\
\text { alguna calidad en } \\
\text { común }\end{array}$ \\
$\begin{array}{llll}\text { Tercera } \\
\text { generación }\end{array}$ & $\begin{array}{l}\text { Derechos o intereses } \\
\text { difusos }\end{array}$ & $\begin{array}{l}\text { Derechos de la } \\
\text { solidaridad o de la } \\
\text { fraternidad }\end{array}$ & $\begin{array}{l}\text { Los pueblos de la } \\
\text { Tierra }\end{array}$ \\
\hline
\end{tabular}

8 Cf. PANAMÁ. CORTE SUPREMA DE JUSTICIA (CSJ). SALA TERCERA. Sent. de 29 jul. 2008 (Acción de protección de DDHH, Fundación Pro Bienestar y Dignidad de Personas Afectadas por el VIH/SIDA (PROBIDSIDA) vs. Ministerio de Salud (MINSA) \& Caja de Seguro Social (CSS)). MP: Adán Arnulfo Arjona L. 
Los DDHH de primera generación, es decir, los primeros en aparecer cronológicamente, son conocidos también como derechos o intereses individuales, y surgieron en el siglo XVIII como resultado de las Revoluciones Estadounidense y Francesa, que fueron reacciones sociales de afirmación de los individuos frente al absolutismo monárquico. ${ }^{9}$ Los bienes de la personalidad tutelados por los derechos de esta generación son los denominados derechos civiles y políticos o de la libertad. Los primeros incluyen, entre otros, los derechos a la vida y a la integridad personal, la igualdad ante la Ley, las garantías penales, y las libertades personal, de expresión, de reunión, de asociación, de culto, etc., mientras que los segundos giran principalmente en torno a los derechos a elegir y ser elegido, y a la participación política. ${ }^{10}$ Son titulares de estos derechos, como es fácil adivinar, las personas. ${ }^{11}$

Por su parte, los DDHH de segunda generación, llamados derechos o intereses colectivos, aparecieron en el siglo XIX, inicialmente como resultado de la reacción de los trabajadores organizados frente a las terribles condiciones laborales impuestas por la Revolución Industrial, pero posteriormente fueron extendiéndose a otras áreas relacionadas con el bienestar general de la sociedad. ${ }^{12}$ Los bienes de la personalidad tutelados por los derechos de esta generación son los denominados derechos económicos, sociales y culturales (Desc) o de la igualdad, que incluyen los siguientes derechos: al trabajo (y demás derechos comprendidos por éste, tales como los de sindicación, huelga, salario justo, jornada máxima, descanso semanal obligatorio, etc.), a la salud, a la educación y a la vivienda, así como los derechos de las minorías nacionales, lingüísticas, étnicas y raciales, y de los grupos más vulnerables, como las mujeres, los niños, los

9 Cf. IEPALA, III.C. Los derechos de la primera generación: los derechos civiles y políticos. Caracteres.

${ }^{10}$ Cf. IEPALA, III.C. Los derechos de la primera generación: Ios derechos civiles y políticos. Clasificación.

${ }^{11}$ Cf. INSTITUTO DE ESTUDIOS POLÍTICOS PARA AMÉRICA LATINA Y ÁFRICA - IEPALA. Curso Sistemático de Derechos Humanos (DDHH), Jesús Lima Torrado \& Fernando Rovetta, Coordinadores, Madrid, 1996, II.B.7.2. En relación a los sujetos titulares de los bienes de la personalidad.

12 Cf. IEPALA, III.D. Los derechos de segunda generación: derechos económicos, sociales y culturales. Caracteres. 
adultos mayores y los discapacitados, entre otros. ${ }^{13}$ La titularidad sobre estos derechos reside en la colectividad como un todo, o bien en aquellos grupos de personas cuyos integrantes comparten alguna calidad en común (v.g. los residentes de una calle o barrio, los miembros de un sindicato o gremio, los jubilados, etc.). ${ }^{14}$

Finalmente, encontramos los DDHH de tercera generación, que también se conocen como derechos o intereses difusos. Éstos aparecieron en la segunda mitad del siglo XX, en forma posterior a la Segunda Guerra Mundial, ${ }^{15}$ y en su desarrollo ha jugado un importante papel la Organización de las Naciones Unidas (ONU). Los bienes de la personalidad tutelados por los derechos de esta generación son los denominados derechos de la solidaridad o de la fraternidad, entre los cuales se cuentan el derecho a un ambiente sano, al desarrollo, a la autodeterminación y a la paz. ${ }^{16}$ La titularidad sobre estos derechos reside en los pueblos de la Tierra. ${ }^{17}$

La anterior división no es perfecta ni exacta, testimoniando así lo que Iepala ha denominado "la ambigüedad conceptual y terminológica de los derechos humanos". ${ }^{18}$ Por ejemplo, Iepala se refiere a los DDHH de segunda y tercera generación como derechos o intereses colectivos, ${ }^{19}$ la actual Constitución colombiana califica a ciertos DDHH de tercera generación como derechos colectivos, ${ }^{20}$ y como veremos más adelante,

${ }^{13}$ Cf. IEPALA, III.D. Los derechos de segunda generación: derechos económicos, sociales y culturales. Clasificación.

${ }^{14}$ Supra, nota 5.

${ }^{15}$ Cf. IEPALA, III.E. Los derechos de tercera generación: derechos de los pueblos o derechos de solidaridad. Caracteres.

${ }^{16}$ Cf. IEPALA, III.E. Derechos de tercera generación: derechos de los pueblos o derechos de solidaridad. Clasificación.

17 Supra, nota 5.

${ }^{18}$ Cf. IEPALA, II.B.2.1. La ambigüedad conceptual y terminológica de los derechos humanos.

19 Supra, nota 5.

${ }^{20}$ Cf. COLOMBIA. Constitución Política de 1991, reformada en 1993, 1995, 1996, 1997, 1999, 2000 , 2001, 2002, 2003, 2004 y 2005. Political Database of the Americas, Center for Latin American Studies, Edmund A. Walsh School of International Service, Georgetown University, Washington, Nov. 2008 (en adelante Constitución colombiana). 
los instrumentos del Sistema Interamericano de Protección de DDHH contemplan el derecho a un ambiente sano como parte de los Desc.

La fórmula de Vašák tampoco ha estado exenta de críticas, entre las cuales se destaca la del jurista brasileño Antonio Cançado Trindade, ex juez de la Corte Interamericana de DDHH (Corte IDH) y actual juez de la Corte Internacional de Justicia (CIJ), quien llega a calificarla de "históricamente inexacta y jurídicamente infundada", ${ }^{21}$ si bien reconoce su "posible mérito pedagógico o quizás literario". 22

De cualquier modo, no puede soslayarse el hecho que

el modelo de Vašák es, por supuesto, una expresión simplificada de un registro histórico extremadamente complejo, y no es su intención la de sugerir un proceso lineal en el cual cada generación le da origen a la próxima y luego fenece. Tampoco implica que una generación sea más importante que la otra. Las tres generaciones se entienden como acumulativas, traslapadas, y, es importante señalar, interdependientes e interdiscernibles (ENCYCLOPÆDIA BRITANNICA, 2009a, Traducción libre).

\section{Los derechos o intereses difusos y las obligaciones internacionales de los Estados americanos en materia de derechos económicos, sociales y culturales (Desc)}

La naturaleza jurídica de los derechos o intereses difusos implica necesariamente que, para una adecuada tutela de los mismos, y en particular del derecho a un ambiente sano, los Estados se ajusten a los estándares vinculantes desarrollados por las distintas fuentes que integran

${ }^{21}$ CANÇADO TRINDADE, Antonio. "Reflexiones sobre el Futuro del Sistema Interamericano de Protección de los Derechos Humanos", en VARIOS. El Futuro del Sistema Interamericano de Protección de los Derechos Humanos, Juan E. Méndez \& Francisco Cox, eds., Instituto Interamericano de Derechos Humanos, San José, t. 1, 1994, p. 39 y ss. Cit. por García Ramírez (2004, p. 88, nota 6).

22 CANÇADO TRINDADE, Antonio. 1994, p. 39 apud García Ramírez (2004, p. 88, nota 6). 
el llamado corpus iuris del Derecho Internacional de los DDHH, los cuales esbozaremos a continuación.

Tomando en cuenta la profunda dimensión ética y la creciente universalización de los DDHH (UPRIMNY YEPES; UPRIMNY YEPES; PARRA VERA, 2006, p. 12), es un hecho cada vez más cierto que su exigibilidad ES independiente de su reconocimiento por parte de los Estados (MORENO CRUZ, 2007, p. 825-852), y que su promoción, protección y defensa trascienden las fronteras nacionales (AIDA, 2008, p. 1-7). Sin embargo, no podemos ignorar que, como afirma el jurista peruano Diego García-Sayán, juez de la Corte IDH,

si bien la universalización de los derechos humanos de la que nos habla Norberto Bobbio ha sido una etapa sustancial para la consolidación de la protección de los derechos humanos básicamente cumplida, en la actualidad el desafío es el de la 'nacionalización' de los derechos humanos como camino para hacerlos efectivos (GARCÍA-SAYÁN, 2005 p. 326).

Tampoco podemos soslayar que los sujetos del Derecho Internacional siguen siendo los Estados, al igual que los organismos internacionales por ellos constituídos. ${ }^{23}$

De allí que, en la actualidad, los tratados internacionales sean la fuente primaria del Derecho Internacional de los DDHH, lo cual refleja que las corrientes jurídicas positivista y voluntarista siguen imperando en las relaciones entre los Estados (IBARGÜEN BURGOS, 2003, p. 33), pero también expresa la voluntad política de la comunidad internacional de unificar sus estándares en la materia.

La mayoría de estos tratados ofrece un grado más alto de protección a los DDHH de primera generación, ${ }^{24}$ aunque ello no quiere decir que no protejan a las otras dos generaciones de DDHH, como explicaremos en el presente trabajo. En el Sistema Interamericano, el principal

\footnotetext{
23 Para una visión alternativa, Vid. Philip Allott (2002, p. 1486).

${ }^{24}$ Cf. IEPALA, II.B.3. Caracteres de los derechos humanos.
} 
de aquellos es la Convención Americana sobre DDHH (CADH), también conocida como Pacto de San José (1969), que crea los dos órganos de control de dicho sistema: la Comisión Interamericana de DDHH (CIDH) y la Corte IDH. ${ }^{25}$ Las violaciones a los derechos consagrados en la $\mathrm{CADH}$, que sean imputables a cualquiera de los Estados Partes de la misma, pueden ser examinadas a través del sistema de peticiones individuales de la $\mathrm{CIDH}$ (CADH, art. 44-51), pero sólo aquellos Estados Partes que hayan reconocido expresamente la competencia de la Corte IDH pueden ser demandados ante ésta por la CIDH, juzgados y declarados internacionalmente responsables por ésta en función de tales violaciones ( $\mathrm{CADH}$, art. 62). Es importante agregar que, en los casos que involucren a un Estado miembro de la OEA que aún no haya ratificado la $\mathrm{CADH}$, la $\mathrm{CIDH}$ puede examinar comunicaciones por violaciones a los DDHH incluidos en la Declaración Americana de los Derechos del Hombre, pero no puede demandar a dicho Estado ante la Corte IDH. ${ }^{26}$

Si bien la protección de la familia y los derechos del niño cuentan con disposiciones convencionales específicas en el capítulo II (Derechos Civiles y Políticos) de la CADH (art. 17 y 19), ésta hace referencia expresa a los Desc en su capítulo III (Derechos Económicos, Sociales y Culturales) que consta de un solo artículo: el 26, que impone a los Estados la obligación de desarrollo progresivo de los Desc.

Como explica el jurista costarricense Manuel E. Ventura Robles, juez de la Corte IDH, el carácter general de esta disposición convencional obedece a que los Estados miembros de la OEA, oído el dictamen de la $\mathrm{CIDH}$ y "sobre la base de que el Protocolo de Buenos Aires había incorporado nuevas normas económicas, sociales y culturales [a la Carta de la OEA]" (VENTURA ROBLES, 2004, p. 102), optaron por "erradicar la enumeración de estos derechos del proyecto de Convención y por ende no

${ }^{25}$ Cf. Convención Americana sobre Derechos Humanos (CADH) art. 33 y ss. Ratificada por Panamá mediante Ley No. 15 de 28 oct. 1977 (Gaceta Oficial (G.O.) N. 18,468 de 30 nov. 1977).

${ }^{26}$ Cf. Estatuto de la CIDH, art. 20. Aprobado por la Asamblea General de la OEA mediante Resolución No. 447 de 1979, y modificado mediante Resolución No. 1098 de 1991. 
establecer del todo ningún sistema de control en este sentido" (VENTURA ROBLES, 2004, p. 102), por considerar suficiente que la CADH reconociese "la necesidad de adoptar progresivamente, en sus legislaciones internas, las garantías que permitieran la plena vigencia de estos derechos" (VENTURA ROBLES, 2004, p. 102).

Las dos últimas afirmaciones prefiguran la existencia de dos posiciones con respecto a la justiciabilidad del artículo 26 de la CADH. Según la primera de ellas, propugnada entre otros por los juristas estadounidenses James Cavallaro, director ejecutivo del Programa de Derechos Humanos de Harvard Law School, y Emily Schaffer, ex fellow de dicho programa, se trata de una norma convencional programática, y por tanto, no justiciable per se (CAVALLARO; SCHAFFER, 2006, p. 196), mientras que, de acuerdo con la segunda postura, abrazada entre otros por el jurista mexicano Sergio García Ramírez, juez de la Corte IDH, la obligación de desarrollo progresivo establecida por dicha norma convencional es directamente justiciable (GARCÍA RAMÍREZ, 2004, p. 98-100).

La discusión planteada por ambas posturas es similar a la que versa sobre la justiciabilidad de las normas constitucionales programáticas (COLOMER VIADEL, 2006, p. 63), a la cual nos referiremos más adelante. No obstante, al reenfocar dicha discusión desde una perspectiva garantista, que es como deben examinarse las restricciones a los $\mathrm{DDHH}$, no podemos menos que inclinarnos por la segunda tesis, toda vez que la disposición convencional in comento incluye dos indicadores balanceados de cumplimiento: 1) "la plena efectividad de los Desc", y 2) "la medida de los recursos disponibles". Ambos parámetros pueden ser perfectamente utilizados tanto por la CIDH como por la Corte IDH para determinar si un Estado: 1) ha adoptado medidas progresivas "por vía legislativa u otros medios apropiados", 2) no ha hecho nada, ó 3) ha adoptado medidas regresivas que han desmejorado los estándares más altos existentes, sean éstos nacionales o internacionales.

De cualquier modo, el vacío normativo que pudiera haber dejado la CADH ha sido llenado por el Protocolo Adicional a la Convención Americana sobre Derechos Humanos en Materia de Derechos Económicos, 
Sociales y Culturales (PSS), también conocido como Protocolo de San Salvador (1988), cuyo artículo 1 reitera la obligación general de progresividad impuesta a los Estados Partes por el artículo 26 de la $\mathrm{CADH}$.

El PSS también impone a los Estados, en disposiciones separadas, ${ }^{27}$ otras cuatro obligaciones generales:

1) la de adoptar disposiciones de Derecho Interno que hagan efectivos los Desc;

2) la no discriminación en el ejercicio de los Desc;

3) la no admisión de restricciones cuando los estándares establecidos por el Derecho Interno o por tratados internacionales anteriores en materia de Desc sean superiores a los del PSS;

4) la admisión de las restricciones y limitaciones a los Desc únicamente por vía de excepción, así como el alcance de las mismas.

El catálogo de Desc incluidos en el PSS enumera, también en disposiciones separadas (PSS, art. 6-18), los siguientes derechos: al trabajo, a las condiciones justas, equitativas y satisfactorias de trabajo, sindicales, a la seguridad social, a la salud, a un medio ambiente sano, a la alimentación, a la educación, a los beneficios de la cultura, a la constitución y protección de la familia, de la niñez, de los ancianos y a la protección de los minusválidos. ${ }^{28}$

En lo concerniente a la competencia de los órganos de control, el artículo 19.6 del PSS señala expresamente que las violaciones a los derechos a la libertad sindical y a la educación que sean imputables a los Estados Parte pueden ser sometidas al sistema de peticiones individuales de la

${ }^{27}$ Cf. Protocolo Adicional a la Convención Americana sobre Derechos Humanos en Materia de Derechos Económicos, Sociales y Culturales (PSS), art. 2-5. Ratificado por Panamá mediante Ley No. 21 de 22 oct. 1992 (G.O. No. 22,152 de 27 oct. 1992).

${ }^{28}$ Actualmente, el término utilizado por el Sistema Interamericano es el de "personas con discapacidad". Cf. Convención Interamericana para la Eliminación de todas las Formas de Discriminación contra las Personas con Discapacidad. Ratificada por Panamá mediante Ley No. 3 de 10 ene. 2001 (G.O. No. 24, 219 de 15 ene. 2001). 
CIDH (PSS, art. 19.6). Esto ha sido interpretado restrictivamente por los juristas Cavallaro y Schaffer, quienes opinan que, en materia de Desc, los dos órganos de control sólo tienen competencia para examinar y pronunciarse con respecto a violaciones a estos dos derechos (CAVALLARO; SCHAFFER, 2006, p. 230). No obstante, la anterior tesis ha sido rebatida vigorosamente por la jurista estadounidense Tara Melish, asesora legal del Centro por la Justicia y el Derecho Internacional (Cejil), ${ }^{29}$ ONG con sede en Washington, EE. UU., quien la estima contraria a las normas sobre aplicación e interpretación de los tratados internacionales (MELISH, 2006, p. 231, nota 162), contenidas en la Convención de Viena sobre el Derecho de los Tratados (CVDT). ${ }^{30}$

Según dicha autora, la interpretación correcta de esta disposición convencional es la de hacer extensiva, sin restricciones, la competencia de la CIDH y la Corte IDH a los Desc consagrados tanto en el capítulo II de la CADH como en el PSS, por ministerio del artículo 26 de la CADH (MELISH, 2006, p. 229), tesis ésta que nos parece más acorde con el principio favor libertatis o pro persona, que puede resumirse en la siguiente máxima: "En caso de duda se ha de sentenciar en favor de la libertad". ${ }^{31}$ Este criterio es coherente, además, con el artículo 29 de la CADH, cuyas reglas interpretativas informan a todos los instrumentos convencionales del Sistema Interamericano.

Todo lo anterior resulta relevante para nuestro análisis porque, como ya hemos señalado, a pesar que desde el punto de vista doctrinal se trata de un derecho o interés difuso, el derecho a un ambiente sano es uno de los Desc positivizados por el PSS.

Lo cierto es que, precisamente por tratarse de un área que se encuentra en franca evolución, otra de las grandes fuentes del Derecho

${ }^{29}$ CEJIL ha ejercido la representación de las víctimas en los tres casos fallados por la Corte IDH contra Panamá hasta la fecha: Caso Leonidas A. Baena Ricardo y Otros (2001), Caso Heliodoro Portugal (2008) y Caso Santander Tristán Donoso (2009).

${ }^{30}$ Cf. Convención de Viena sobre el Derecho de los Tratados (CVDT), art. 30-32. Ratificada por Panamá mediante Ley No. 17 de 31 oct. 1979 (G.O. 19,106 de 7 jul. 1980).

${ }^{31}$ IEPALA, B.9.3. Las declaraciones de derechos humanos en los siglos XVI, XVII y XVIII. 
Internacional de los DDHH, la jurisprudencia, es todavía muy escasa en materia de Desc (AIDA, 2008, p. 60). Por ejemplo, el juez Ventura menciona como emblemáticos los Casos Aloebotoe vs Suriname (Reparaciones), Comunidad Mayagna (Sumo) Awas Tingni vs Nicaragua, Baena Ricardo y Otros vs Panamá, y Cinco Pensionistas vs Perú (Fondo, Reparaciones y Costas). Los dos primeros versan sobre derechos colectivos indígenas y los dos últimos sobre derechos laborales. El juez Ventura también destaca la relevancia de la Opinión Consultiva OC-18/03 sobre Condición Jurídica y Derechos de los Migrantes Indocumentados (VENTURA ROBLES, 2004, p. 107).

\section{El derecho ambiental panameño a la luz de los estándares interamericanos de DDHH}

\section{La "responsabilidad común pero diferenciada"32 del Estado panameño en materia ambiental}

Si bien es cierto que todos los Estados comparten una responsabilidad común por preservar el planeta Tierra, hogar común de toda la humanidad, a la República de Panamá le cabe una responsabilidad diferenciada de enormes proporciones, no sólo a nivel local, sino también global.

En términos de biodiversidad,

el país se encuentra en la posición 19 entre los 25 países con mayor riqueza de especies de plantas con flores y en la posición número 4 para América del Norte y Central. Panamá tiene cerca del $4 \%$ de la diversidad total de anfibios, el 3,5\% de reptiles, el $10 \%$ de especies de aves conocidas y el $5 \%$ de los mamíferos existentes en el mundo. En cuanto a peces, 140 de las 1,307 especies de peces marinos son de

${ }^{32}$ Cf. ONU. Declaración de Río, Principio 7, Conferencia de las Naciones Unidas sobre el Medio Ambiente y el Desarrollo (CNUMAD), Río de Janeiro, 14 jun. 1992. 
interés comercial y el 25\% (56 especies) de peces de agua dulce son endémicas de Panamá. ${ }^{33}$

Así pues, en su calidad de administrador de este "fideicomiso planetario" (BORRERO NAVIA, 1990, p. 51), nuestro país no puede darse el lujo de dejar este "patrimonio común de la humanidad" (LÓPEZ ZAMARRIPA, 2001, p. 122) a merced de las constantes presiones de la frontera agropecuaria, la actividad industrial y comercial, y el desarrollo urbano. $^{34}$

La creciente escasez mundial de água (UNESCO, 2009, p. 18) se encuentra intrínsecamente ligada al imperativo de conservar nuestros bosques, no sólo para preservar su condición de puente biológico de las Américas (HECKADON-MORENO, 2001), sino también para salvaguardar el derecho al agua ${ }^{35}$ y el funcionamiento del Canal, ${ }^{36}$ honrando de paso la obligación internacional de garantizar su "seguridad, eficiencia y mantenimiento apropiado", asumida a través del segundo de los Tratados Torrijos-Carter. ${ }^{37}$

El papel del istmo de Panamá en la regulación del clima mundial (COATES, 2009) exige que el tema ambiental sea de máxima prioridad para nuestro país, frente al cambio climático global y a las condiciones

33 PANAMÁ. ANAM. Primer Informe del Estado y la Riqueza de la Biodiversidad de Panamá, en PANAMÁ. Segundo Informe. Objetivos de Desarrollo del Milenio, Gabinete Social \& Sistema de las Naciones Unidas, Panamá, sep. 2005, p. 98.

${ }^{34}$ Cf. PANAMÁ. ANAM. Estrategia Nacional del Ambiente. Documento Principal, 2da ed., Panamá, 2002, p. 38. Aprobada por el Consejo de Gabinete mediante Resolución de Gabinete No. 36 de 31 may. 1999 (G.O. 23,811 de 4 jun. 1999).

35 Cf. ONU. COMITÉ DE DERECHOS ECONÓMICOS, SOCIALES Y CULTURALES (DESC). Observación General No. 15. "El Derecho al Agua (artículos 11 y 12 del Pacto Internacional de DESC)", ONU, Consejo Económico y Social (ECOSOC), 20 ene. 2003.

${ }^{36}$ Cf. PANAMÁ. ANAM. Estrategia Nacional del Ambiente. Gestión Ambiental para el Desarrollo Sostenible 2008-2012. 2. ed., Panamá, feb. 2009, p. 27-28. Aprobada por el Consejo de Gabinete mediante Resolución de Gabinete No. 2 de 23 ene. 2009 (G.O. 26,211 de 28 ene. 2009).

${ }^{37}$ Cf. Tratado de Neutralidad Permanente y Funcionamiento del Canal de Panamá, art. II. Ratificado por Panamá mediante Plebiscito de 23 oct. 1977 (G.O. 18,451 de 1 de noviembre de 1977). 
extremas derivadas de éste, las cuales amenazan con agravarse paulatinamente. ${ }^{38}$ Por otro lado, para un país en que la mayor parte del territorio se encuentra a nivel del mar, cuyos límites norte y sur son costeros, y cuya parte más ancha entre los Océanos Atlántico y Pacífico mide apenas 200 kilómetros (ENCYCLOPÆDIA BRITANNICA, 2009b), el calentamiento global, con el consecuente derretimiento de los casquetes polares e incremento en el nivel de los océanos, representa una gravísima amenaza. ${ }^{39}$

No cabe duda entonces que es un imperativo local y global que Panamá se mantenga a la vanguardia en la protección del ambiente.

\section{La relación entre el Derecho Internacional y nuestro Derecho Interno en materia de Desc}

En Panamá, los tratados internacionales son vinculantes por disposición del artículo 4 de la Constitución, cuyo texto actual fue adoptado con la reforma de 1983, que reincorporó a la Carta Fundamental la cláusula pacta sunt servanda contenida en la Constitución de 1946, en reemplazo de la cláusula rebus sic stantibus que fuera introducida por el texto originario de la Constitución de $1972,{ }^{40}$ y que formaba parte de la estrategia panameña para la recuperación del Canal (VEGA REYES, 1999, p. 248).

El texto actual de dicho precepto constitucional fue adoptado como consecuencia de otros dos actos jurídicos:

${ }^{38}$ Cf. PANEL INTERGUBERNAMENTAL DE EXPERTOS SOBRE EL CAMBIO CLIMÁTICO (IPCC, por sus siglas en inglés). Cambio Climático 2007. Informe de Síntesis, IPCC, Ginebra, 2008, pp. 1-22.

${ }^{39}$ Cf. IPCC, Supra, nota 66.

${ }^{40}$ Cf. PANAMÁ. CSJ. PLENO. Sent. de 14 jun. 1990 (Acción de inconstitucionalidad, Juan Materno Vásquez De León contra un Acuerdo y varios Canjes de Notas con los EE. UU.). Magistrada Ponente (MP): Aura Emérita Guerra de Villalaz. El texto originario del artículo 4 de la Constitución decía así: "La República de Panamá acata las normas universalmente reconocidas del Derecho Internacional que no lesionen el interés nacional." Las frases subrayadas fueron derogadas por la reforma de 1983. 
1) la ratificación (1977) y entrada en vigor (1979) de los dos Tratados Torrijos-Carter, el primero de los cuales ${ }^{41}$ subrogó el Tratado Hay-Bunau Varilla suscrito con los EE. UU. (1903), permitiendo así la reversión del Canal de Panamá (1999);

2) la posterior ratificación de la CVDT, cuyo artículo 26 codifica la norma consuetudinaria internacional pacta sunt servanda (KELSEN, 1952, p. 269), elevándola a la categoría de regla general en materia de tratados internacionales.

El artículo 4 de la Constitución y el artículo 26 de la CVDT imponen al Estado panameño dos obligaciones generales:

1) el cumplimiento en sí de los compromisos específicos adquiridos en el texto de un tratado internacional, aun desde la firma del mismo; ${ }^{42}$

2) la adecuación del Derecho Interno a dichos compromisos. ${ }^{43}$

Con respecto a la primera de estas obligaciones generales, cabe destacar que Panamá ha ratificado al menos 28 tratados internacionales ambientales, que le imponen diversos compromisos específicos. ${ }^{44}$ En cuanto a la segunda de tales obligaciones generales, la jurisprudencia interamericana de DDHH ha señalado lo siguiente:

La Corte ha interpretado que tal adecuación implica la adopción de medidas en dos vertientes, a saber: i) la supresión de las normas y prácticas de cualquier naturaleza que entrañen violación a las garantías

${ }^{41}$ Cf. Tratado del Canal de Panamá, Ratificado por Panamá mediante Plebiscito de 23 oct. 1977 (G.O. 18,451 de 1 nov. 1977.

${ }^{42} \mathrm{Cf}$. CORTE INTERAMERICANA DE DERECHOS HUMANOS (CORTE IDH). Caso Baena Ricardo y Otros vs. Panamá, Sent. de 2 feb. 2001 (Fondo, Reparaciones y Costas), párr. 179.

${ }^{43}$ Cf. CADH, art. 2 y Caso Baena Ricardo, párr. 98.

${ }^{44}$ Cf. PANAMÁ. MINISTERIO DE RELACIONES EXTERIORES (MIRE). Tratados Multilaterales Vigentes. Medio Ambiente, Centro de Documentación, Panamá, s.f. 
previstas en la Convención o que desconozcan los derechos allí reconocidos u obstaculicen su ejercicio, y ii) la expedición de normas y el desarrollo de prácticas conducentes a la efectiva observancia de dichas garantías. Precisamente, respecto a la adopción de dichas medidas, es importante destacar que la defensa u observancia de los derechos humanos a la luz de los compromisos internacionales en cuanto a la labor de los operadores de justicia, debe realizarse a través de lo que se denomina "control de convencionalidad", según el cual cada juzgador debe velar por el efecto útil de los instrumentos internacionales, de manera que no quede mermado o anulado por la aplicación de normas o prácticas internas contrarias al objeto y fin del instrumento internacional o del estándar internacional de protección de los derechos humanos. ${ }^{45}$

Como indicamos con anterioridad, el derecho a un ambiente sano ha sido reconocido expresamente por el artículo 11 del PSS, el cual lo considera parte integrante de los Desc. Las dos obligaciones generales a que nos hemos venido refiriendo se desprenden claramente de sus numerales 1 y 2 .

Por otro lado, debemos recordar que, como ha dicho el juez Cançado Trindade, "el derecho a un medio ambiente sano es un corolario del derecho a la vida" ${ }^{46}$ que está protegido por el artículo 4.1 de la CADH. El estándar interamericano sobre el derecho a la vida, establecido en esta disposición convencional, obliga a los Estados a respetar la vida de todas las personas y les prohíbe privarlas arbitrariamente de ella.

Una interpretación a contrario sensu de esta disposición convencional permite concluir que, si la privación de la vida no fuese arbitraria, entonces no estaría proscrita por dicha norma. Por tanto, en el Sistema Interamericano, el derecho a la vida no está protegido en términos

45 Cf. CORTE IDH. Caso Heliodoro Portugal vs. Panamá, Sent. de 12 ago. 2008 (Excepciones Preliminares, Fondo, Reparaciones y Costas), párr. 180. Énfasis añadido.

${ }^{46}$ CANÇADO TRINDADE, Antonio. The Contribution of International Human Rights Law to Environmental Protection, with Special Reference to Global Environmental Change, en VARIOS. Environmental Change and International Law: New Challenges and Developments, Edith Brown Weiss, Ed., 1992, p. 274. Cit. por Orellana (2008, p. 292). 
absolutos, sino que admite restricciones (PIZARRO SOTOMAYOR; MÉNDEZ POWELL, 2006, p. 45).

El anterior razonamiento se fundamenta en que, al momento de aprobarse la $\mathrm{CADH}$, el derecho a la vida se entendía únicamente en función de la pena de muerte, protegiéndose el derecho a no ser arbitrariamente condenado a muerte. No obstante, la Corte IDH ha ampliado el reconocimiento del derecho a la vida, formulando el concepto de "derecho a una vida digna", según el cual, por ejemplo, el desproveer de agua potable, alimentación y salud a una comunidad constituye una violación del derecho a la vida, ${ }^{47}$ lo cual incide de modo relevante en la tutela del derecho a un ambiente sano.

En materia ambiental, la jurisprudencia de la Corte IDH ha sido igualmente escasa y tangencial, tal como ha ocurrido con el resto de los Desc. Así, por ejemplo, la Asociación Interamericana para la Defensa del Ambiente (Aida), ONG con sede en México, D.F., menciona los casos de las Comunidades Indígenas Mayagna (Awas) Tingni vs Nicaragua, Yakye Axa vs Paraguay, y Sawhoyamaxa vs Paraguay, y el caso Claude Reyes vs Chile, este último sobre acceso a la información (AIDA, 2008, p. 59-63).

\section{El desarrollo progresivo del Derecho Ambiental panameño}

En los apartados anteriores, expusimos someramente cuáles son los compromisos internacionales adquiridos por Panamá en materia de Desc. A continuación, se examinará cómo Panamá ha dado cumplimiento a la obligación general de adecuar su normativa interna.

Históricamente, Panamá ha sido pionera en la protección del derecho a un ambiente sano. Según el extinto jurista chileno Raúl Brañes Ballesteros, la Constitución panameña (1972) fue la primera en Latinoamérica en consagrar esta obligación del Estado, al igual que el deber de

${ }^{47}$ Cf. CORTE IDH. Caso de la Comunidad Indígena Yakye Axa vs. Paraguay, Sent. de 17 jun. 2005, (Fondo, Reparaciones y Costas), párrs. 160-176. 
promover el desarrollo sostenible ${ }^{48}$ incluso antes que el término fuese acuñado internacionalmente por la Comisión Brundtland (1987). ${ }^{49}$

Tal como señalamos a propósito de la normativa interamericana, las disposiciones pertenecientes al Régimen Ecológico de la Constitución ${ }^{50}$ deben ser leídas en concordancia con el estándar nacional sobre el derecho a la vida, contenido en el artículo 17 de la Constitución.

Una interpretación a contrario sensu del párrafo primero de dicho precepto nos lleva necesariamente a la conclusión que el derecho a la vida se encuentra reconocido en dicha norma, mientras que si lo interpretamos literalmente, la conclusión es que el Estado está obligado a garantizar este derecho, "protegiéndolo" y "asegurando su efectividad". Ello es congruente con el artículo 4.1 de la CADH. Por otra parte, utilizando una interpretación finalista, es decir, que atienda al fin perseguido por la norma, ${ }^{51}$ es razonable concluir que el derecho a la vida resulta vulnerado cuando el Estado crea, por acción u omisión, las condiciones para que se produzca el resultado muerte, aun cuando éste no se haya producido. ${ }^{52}$

Se observa entonces que, en lo concerniente al derecho a la vida, el estándar nacional es superior al internacional, toda vez que el artículo 17 de la Constitución no admite restricciones en el cumplimiento de dicha obligación y la pena de muerte está prohibida constitucionalmente..$^{53}$

${ }^{48}$ Cf. BRAÑES BALLESTEROS, Raúl. "El derecho para el desarrollo sostenible en la América Latina de nuestros días", Revista de Derecho Ambiental, n. 2, p. 22, 2006. Centro de Derecho Ambiental, Facultad de Derecho, Universidad de Chile, y PANAMÁ. Constitución Política de 1972, reformada en 1978, 1983, 1994 y 2004, art. 118 y 119 (en adelante Constitución panameña). El artículo 110 del texto originario, al que se refirió Brañes, decía así: “Es deber fundamental del Estado velar por las condiciones ecológicas, previniendo la contaminación del ambiente y el desequilibrio de los ecosistemas, en armonía con el desarrollo económico y social."

49 COMISIÓN MUNDIAL SOBRE AMBIENTE Y DESARROLLO (COMISIÓN BRUNDTLAND). Our Common Future. Oslo, 20 mar. 1987, párr. 27.

${ }^{50}$ Cf. Constitución panameña, art. 118-121.

${ }^{51}$ Cf. CORTE IDH. Caso de la Comunidad Indígena Sawhoyamaxa vs. Paraguay, Sent. de 29 mar. 2006 (Fondo, Reparaciones y Costas), Voto Razonado del Juez Sergio García Ramírez, párr. 19.

52 Supra, nota 9.

${ }^{53}$ Cf. Constitución panameña, art. 30. 
Cuando ello ocurre en materia de protección de DDHH, prevalece el estándar nacional, el cual no puede ser desmejorado posteriormente por el Estado, a la luz de lo que establece el artículo 29 de la CADH, al cual ya hemos hecho referencia.

En lo concerniente al desarrollo progresivo del derecho a un ambiente sano a nivel legal y reglamentario, se han creado en total 65 áreas protegidas que cubren el 34,43\% del territorio nacional, ${ }^{54}$ a través de leyes, decretos ejecutivos, resoluciones administrativas de entidades descentralizadas e incluso acuerdos municipales, ${ }^{55}$ la mayoría de ellas durante la segunda mitad del siglo pasado. En ese mismo período, fueron aprobadas leyes sectoriales sobre recursos hídricos, ${ }^{56}$ recursos forestales, ${ }^{57}$ y áreas protegidas y vida silvestre, ${ }^{58}$ hasta llegar finalmente a la Ley General de Ambiente (LGA), ${ }^{59}$

${ }^{54}$ Cf. PANAMÁ. ANAM. Informe. El Sistema Nacional de Áreas Protegidas, Panamá, 2006, p. 9. La primera área protegida de nuestro país fue el Bosque Municipal "El Colmón de Macaracas" (1918). Cf. ANAM. p. 8, y PANAMÁ. ASAMBLEA NACIONAL. Ley n. 27 de 27 dic. 1918, "Por la cual se declaran inadjudicables en propiedad unas tierras nacionales", art. 3 (G.O. 3,021 de 20 ene. 1919).

${ }^{55}$ Cf., p. 10-11.

${ }^{56}$ Vid. PANAMÁ. COMISIÓN LEGISLATIVA PERMANENTE. Decreto Ley n. 35 de 22 sep. 1966, "Mediante el cual se reglamenta el uso de las aguas" (G.O. 15,725 de 14 oct. 1966).

57 Vid. PANAMÁ. ASAMBLEA LEGISLATIVA. Ley No. 1 de 3 feb. 1994, "Por la cual se establece la Legislación Forestal en la República de Panamá y se dictan otras disposiciones" (G.O. 22,470 de 7 feb. 1994).

58 Vid. PANAMÁ. ASAMBLEA LegISLATIVA. Ley No. 24 de 7 jun. 1995, "Por la cual se establece la Legislación de Vida Silvestre en la República de Panamá y se dictan otras disposiciones", G.O. 22,801 de 7 jun. 1995. Modificada y adicionada mediante Ley n. 39 de 24 nov. 2005 (G.O. 25,433 de 24 nov. 2005).

59 Vid. PANAMÁ. ASAMblea legislativa. Ley n. 41 de 1 jul. 1998, "General de Ambiente de la República de Panamá" (LGA), G.O. 23,578 de 3 jul. 1998. Modificada mediante: 1) Ley n. 44 de 23 nov. 2006, "Que crea la Autoridad de los Recursos Acuáticos de Panamá, unifica las distintas competencias sobre los recursos marino-costeros, la acuicultura, la pesca y las actividades conexas de la administración pública y dicta otras disposiciones" (G.O. 25,680 de 27 nov. 2006); y 2) Ley No. 18 de 24 ene. 2003, "Que crea los corregimientos Las Llanas, segregado del corregimiento La Pitaloza, en el distrito de Los Pozos, provincia de Herrera, y San José, segregado del corregimiento San Juan, en el distrito de San Francisco, provincia de Veraguas; modifica los artículos 22 y 64 de la Ley 58 de 1998, y adopta otras disposiciones" (G.O. 24,731 de 31 ene. 2003), art. 10. Al momento de redactar este trabajo, se encuentra pendiente de segundo debate en la Asamblea Nacional el Proyecto de Ley No. 462, que la modifica. 
que cumplió su primer decenio en julio de 2008 y en cuya aprobación fue determinante la participación de la sociedad civil organizada. ${ }^{60}$

Con la aprobación de la LGA, se creó la Autoridad Nacional del Ambiente (Anam) (LGA, art. 5) y se estableció el Sistema Interinstitucional del Ambiente (SIA), integrado por las Unidades Ambientales Sectoriales (UAS) de todas las instituciones del Estado con competencias ambientales (LGA, art. 16). Durante la primera década del siglo XXI, se han dictado leyes especiales en materia de administración de cuencas hidrográficas, ${ }^{61}$ delitos contra el ambiente ${ }^{62}$ y ordenamiento territorial para el desarrollo urbano, ${ }^{63}$ así como decretos ejecutivos reglamentarios en materia de comisiones consultivas y denuncias administrativas, ${ }^{64}$ aprobación de normas de calidad ambiental, ${ }^{65}$ evaluación de impacto ambiental, ${ }^{66}$ organización de la Anam, ${ }^{67}$ vida silvestre,${ }^{68}$ evaluación de auditorías ambientales y

${ }^{60}$ Un recuento histórico de este proceso puede ser consultado en WING SOLís, Op. cit., p. 122 y ss.

${ }^{61} \mathrm{Vid}$. PANAMÁ. ASAMBLEA LEGISLATIVA. Ley n. 44 de 5 ago. 2002, "Que establece el Régimen Administrativo Especial para el manejo, protección y conservación de las cuencas hidrográficas de la República de Panamá" (G.O. 24,613 de 8 ago. 2002).

62 Vid. PANAMÁ. ASAMBLEA NACIONAL. Leyn. 5 de 28 ene. 2005, “Que adiciona un Título, denominado Delitos contra el Ambiente, al Libro II del Código Penal, y dicta otras Disposiciones" (G.O. 25,233 de 4 feb. 2005. Derogado por el cap. XIII del nuevo Código Penal, Ley n. 14 de 18 may. 2007 (G.O. 25,796 de 22 may. 2007).

${ }^{63}$ Vid. PANAMÁ. ASAMBLEA NACIONAL. Ley n. 6 de 1 feb. 2006, "Que reglamenta el ordenamiento territorial para el desarrollo urbano y dicta otras disposiciones" (G.O. 25,478 de 2 feb. 2006).

${ }^{64}$ Vid. PANAMÁ. MINISTERIO DE ECONOMÍA Y FINANZAS (MEF). Decreto Ejecutivo (D.E.) n. 57 de 16 mar. 2000, "Por el cual se reglamenta la Conformación y Funcionamiento de las Comisiones Consultivas Ambientales" (G.0. 24,014 de 21 mar. 2000).

65 Vid. PANAMÁ. MEF. D.E. n. 58 de 16 mar. 2000, "Por el cual se reglamenta el Procedimiento para la Elaboración de Normas de Calidad Ambiental y Límites Máximos Permisibles" (G.O. 24,014 de 21 mar. 2000).

${ }^{66}$ Vid. PANAMÁ. MEF. D.E. n. 59 de 16 mar. 2000, "Por el cual se reglamenta el cap. Il del Título IV de la Ley 41 de 1 jul. 1998, General de Ambiente de la República de Panamá" (G.O. 24,015 de 22 de marzo de 2000). Derogado por el D.E. No. 209 de 5 sep. 2006 (G.O. 25,625 de 6 sep. 2006).

67 Vid. PANAMÁ. MEF. D.E. n. 207 de 7 sep. 2000, “Por medio del cual se establece la nueva estructura organizacional y funciones adoptada por la Autoridad Nacional del Ambiente y presentada al Ejecutivo, por conducto del Ministerio de Economía y Finanzas, tal como se describe en la Ley 41 de 1 jul. 1998" (G.O. 24,137 de 12 sep. 2000).

${ }^{68}$ Vid. PANAMÁ. MEF. D.E. n. 43 de 7 jul. 2004, “Que reglamenta la Ley 24 de 7 jun. 1995 y dicta otras Disposiciones" (G.O. 25,091 de 12 jul. 2004). 
programas de adecuación y manejo ambiental, ${ }^{69}$ recursos bio-genéticos, ${ }^{70}$ funcionamiento del SIA, ${ }^{71}$ entre otros, sin mencionar las incontables resoluciones administrativas que regulan diversas materias con mayor detalle.

Vemos pues que Panamá ha sido prolija en fortalecer paulatinamente su legislación e institucionalidad ambientales, buscando cumplir así con su obligación internacional de desarrollo progresivo de los Desc, al menos en los planos normativo e institucional. La mayoría de las normas ambientales panameñas forman parte de nuestro Derecho Administrativo, si bien su naturaleza jurídica sigue estando ubicada dentro del ámbito de los DDHH. ${ }^{72}$

\section{La tutela judicial del derecho a un ambiente sano en Panamá}

Si bien es cierto que todavía hace falta reglamentar un número plural de materias previstas en la LGA y en las normas ambientales sectoriales y complementarias, ${ }^{73}$ y que siempre habrá necesidad de aprobar nuevas normas o actualizar las vigentes, existe consenso a nivel mundial, en el sentido que una parte sustancial del esfuerzo de los Estados debe encaminarse a lograr la completa y adecuada aplicación de la Ley. ${ }^{74}$ A este

69 Vid. PANAMÁ. MEF. D.E. n. 57 de 10 ago. 2004, "Por el cual se reglamentan los art. 41 y 44 del cap. IV del Título IV, de la Ley 41 de 1 jul. 1998, General de Ambiente de la República de Panamá" (G.O. 25,115 de 13 ago. 2004).

70 Vid. PANAMÁ. MEF. D.E. No. 257 de 17 oct. 2006, "Que reglamenta el art. 71 de la Ley 41 de 1 jul. 1998, General de Ambiente" (G.O. 25,660 de 25 oct. 2006). Derogado por el D.E. 25 de 29 abr. 2009 (G.O. 26,272 de 30 abr. 2009).

71 Vid. PANAMÁ. MEF. D.E. n. 314 de 19 dic. 2006, "Que aprueba el reglamento del art. 16 de la Ley 41 de 1 jul. 1998, para el funcionamiento del Sistema Interinstitucional del Ambiente" (G.O. 25,700 de 28 dic. 2006).

72 Cf. Curso de Derecho Ambiental, p. 34.

${ }^{73}$ Un listado completo de las materias contenidas en la LGA que requieren desarrollo reglamentario puede ser consultado en WING SOLÍS, Op. cit., pp. 141-143.

74 Cf. INTERNATIONAL NETWORK FOR ENVIRONMENTAL COMPLIANCE AND ENFORCEMENT (INECE). Implementing Environmental Legislation: The Critical Role of Enforcement and Compliance, 4th IUCN Academy of Environmental Law Colloquium, Pace Law School, White Plains, 16-20 oct. 2006. 
respecto, el papel de la judicatura es de suma importancia, no sólo como "freno y contrapeso" de la acción administrativa, sino también como orientadora de la misma, y como instrumento para el desarrollo progresivo del derecho a un ambiente sano.

\section{Mecanismos tutelares y objeto procesal}

En Panamá, el control constitucional objetivo o nomofiláctico se da a través de la acción pública de inconstitucionalidad, de competencia privativa del Pleno de la CSJ, que puede ser ejercitada contra "leyes, decretos, acuerdos, resoluciones y demás actos [...] por razones de fondo o de forma". ${ }^{75}$

El control constitucional subjetivo u homofiláctico se da principalmente a través de la acción de amparo, ${ }^{76}$ que puede ser ejercitada por la persona afectada por una orden de hacer o de no hacer dictada por un funcionario público, ${ }^{77}$ y cuyo conocimiento es de competencia de los Juzgados de Circuito del Ramo Civil, los Tribunales Superiores de Distrito Judicial del mismo ramo, o el Pleno de la CSJ, según la jurisdicción territorial de la autoridad que dictó la orden. ${ }^{78}$

Otro mecanismo tutelar de carácter subjetivo, ya en la esfera del control de legalidad, es la acción contencioso-administrativa de protección de DDHH, que puede ejercitarse contra actos administrativos emitidos por autoridades nacionales que violen DDHH, la cual es de competencia de la Sala Tercera de la CSJ. ${ }^{79}$

75 Cf. Constitución panameña, art. 206, num. 1.

76 Cf. PANAMÁ. CSJ. PLENO. Auto de 31 may. 1993 (Acción de amparo, La Confianza, S.A. vs. Contralor General de la República). MP: Fabián A. Echevers.

77 Cf. Constitución panameña, art. 54. Las otras dos acciones de control constitucional subjetivo son el hábeas corpus y el hábeas data.

${ }^{78}$ Cf. PANAMÁ. Código Judicial. Texto Único, art. 2616. Adoptado por la Comisión de Gobierno, Justicia y Asuntos Constitucionales de la Asamblea Legislativa, y el Pleno de la CSJ mediante Resolución No. 1 de 30 ago. 2001 (G.O. 24,384 de 10 sep. 2001).

79 Cf. Código Judicial, art. 97, num. 15. 
La ubicación de la acción de amparo dentro del capítulo I (Garantías Fundamentales) del título I (Derechos y Deberes Individuales y Sociales) de la Constitución, integrado principalmente por derechos civiles y políticos, nos lleva a concluir que la misma fue concebida originalmente para tutelar DDHH de primera generación, lo cual es corroborado por la historia constitucional de nuestro país. ${ }^{80}$ De hecho, tal criterio fue adoptado originalmente por la Sala Tercera de la CSJ con respecto a la acción de protección de DDHH. ${ }^{81}$

No obstante, con la reforma de 2004, se incorporó al artículo 17 del texto constitucional una cláusula de derechos innominados, muy similar a la colombiana, ${ }^{82}$ extendiendo dicho mecanismo tutelar a los DDHH de segunda y tercera generación, entre los cuales se cuenta el derecho a un ambiente sano. Este criterio fue avalado recientemente por la Sala Tercera de la CSJ, que interpretó dicho precepto constitucional en concordancia con los artículos 1.1, 2 y 26 de la $\mathrm{CADH} .^{83}$

También es digna de mención, a la luz de la participación ciudadana en la toma de decisiones en materia ambiental, ${ }^{84}$ la acción de hábeas data, que garantiza el acceso a la información de fuentes públicas, creada primero mediante disposición legal, ${ }^{85} \mathrm{y}$ luego constitucionalizada y ampliada con la reforma de $2004 .^{86}$

${ }^{80}$ La acción de amparo fue introducida por primera vez en nuestro ordenamiento jurídico por la Constitución Política de 1941, con la intención de garantizar los derechos individuales. Cf. MOSCOTE, José D. El Derecho Constitucional Panameño. Antecedentes, Doctrinas y Soluciones. Panamá: Universidad de Panamá, 1960, p. 178-180.

${ }^{81}$ Cf. PANAMÁ. CSJ. SALA TERCERA. Auto de 1 nov. 1995 (Acción de protección de DDHH, Lina Vega Abad vs. Instituto Nacional de Recursos Naturales Renovables (INRENARE) \& Ministerio de Obras Públicas (MOP)). MP: Edgardo Molino Mola.

82 Cf. Constitución colombiana, art. 94.

${ }^{83}$ Cf. PANAMÁ. CSJ. SALA TERCERA. Sent. de 27 nov. 2008 (Acción de protección de DDHH, Syngenta, S.A. vs. Dirección Nacional de Sanidad Vegetal del Ministerio de Desarrollo Agropecuario). MP: Adán Arnulfo Arjona L.

${ }^{84}$ Cf. Declaración de Río, Principio 10.

${ }^{85}$ Cf. PANAMÁ. ASAMBLEA LEGISLATIVA. Ley n. 6 de 22 ene. 2002, "Que dicta normas para la transparencia en la gestión pública, establece la acción de Hábeas Data y dicta otras disposiciones" (G.O. 24,476 de 23 ene. 2002).

${ }^{86} \mathrm{Cf}$. Constitución panameña, art. 44. 


\section{Legitimación procesal}

La Sala Tercera de la CSJ reconoció en forma temprana la legitimación procesal activa de cualquier persona para pedir el reconocimiento de derechos o intereses difusos, a través de la acción contencioso-administrativa de plena jurisdicción, ${ }^{87}$ a pesar que el objeto de dicho mecanismo procesal es "una reparación por lesión de derechos subjetivos". 88 Posteriormente, a través de la LGA, este criterio jurisprudencial cristalizó en materia administrativa y fue ampliado a las jurisdicciones civil y penal. ${ }^{89}$ Años después, la Sala Tercera le dio un nuevo giro a esta legitimación procesal activa, al reconocer que la misma le asiste incluso a los representantes del Ministerio Público, cuando demandan la nulidad de un acto administrativo en función de derechos o intereses difusos..$^{90}$

En cuanto a legitimación procesal pasiva, la LGA prevé un régimen de triple responsabilidad ambiental independiente, en materia administrativa, civil y penal, por daños al ambiente, por lo que cualquier persona puede ser encontrada responsable, en cualquiera de estas tres esferas o en todas, por el mismo hecho generador de riesgo o daño ambiental. ${ }^{91}$

\section{Justiciabilidad del derecho a un ambiente sano a nivel constitucional}

Tras la vuelta a la democracia (1990), le correspondió al Pleno de la CSJ interpretar por primera vez, por vía de la acción de inconstitucionalidad,

${ }^{87}$ Cf. PANAMÁ. CSJ. SALA TERCERA. Auto de 12 mar. 1993 y Sent. de 22 jun. 1994 (Acción de plena jurisdicción, Asociación Nacional para la Conservación de la Naturaleza (ANCON) vs. INRENARE). MP: Arturo Hoyos.

88 PANAMÁ. ASAMBLEA NACIONAL. Ley n. 33 de 11 sep. 1946, "Por la cual se reforma la Ley 135 de 1943, Orgánica de la Jurisdicción Contencioso Administrativa” (G.O. 10,113 de 2 oct. 1946), art. 27.

${ }^{89}$ Cf. LGA, art. 111.

${ }^{90}$ Cf. PANAMÁ. CSJ. SALA TERCERA. Auto de 28 jul. 2004 (Acción de nulidad, Fiscal Quinto de Circuito del Primer Circuito Judicial de Panamá contra dos Resoluciones de Gabinete y un Contrato Administrativo). MP: Adán Arnulfo Arjona L.

${ }^{91}$ Supra, nota 124. 
los artículos del Régimen Ecológico de la Constitución, los cuales fueron declarados normas programáticas, y por tanto, no justiciables. ${ }^{92}$ Otro tanto ocurrió en repetidas ocasiones con el artículo 17 de la Constitución, que consagra el derecho a la vida (y que en aquella época se circunscribía a su actual párrafo primero), aun cuando este derecho sea considerado como "prerrequisito para el disfrute de todos los demás DDHH" ${ }^{93}$ y materia de jus cogens. ${ }^{94}$

Las anteriores interpretaciones prevalecieron hasta que la reforma de 2004 adicionó al artículo 17 la cláusula de derechos innominados a la que ya hicimos referencia, hoy contenida en su segundo párrafo. El antiguo criterio puede encontrarse aún en múltiples fallos posteriores a dicha reforma. Sin embargo, en los últimos años, el Pleno de la CSJ ha accedido en varias ocasiones a examinar y pronunciarse por vía de amparo sobre cargos de violación a dicho artículo, aunque por el momento sólo lo ha hecho indirectamente, es decir, en conjunto con otros preceptos constitucionales, entendiéndose que el mismo impone al Estado una obligación de carácter general. ${ }^{95}$

Lo anterior nos lleva a pensar que es cuestión de tiempo antes que el Pleno de la CSJ acceda a pronunciarse en el fondo, por vía de amparo, sobre violaciones al Régimen Ecológico de la Constitución. No obstante, ello aún no ha ocurrido.

Para concluir este punto, vale la pena reiterar el criterio esbozado por el extinto constitucionalista panameño César A. Quintero Correa (1999, p. 43), el cual ya hemos citado en anteriores trabajos: ${ }^{96}$

92 Cf. PANAMÁ. CSJ. PLENO. Sent. de 13 sep. 1996 (Acción de inconstitucionalidad, Sociedad Audubon de Panamá contra la Ley No. 29 de 23 jun. 1995). MP: Arturo Hoyos.

${ }^{93}$ CORTE IDH. Caso Villagrán Morales vs. Guatemala (Niños de la Calle), Sent. de 19 nov. 1999 (Fondo), párr. 144.

${ }^{94} \mathrm{Cf}$. Ibíd., Voto Concurrente Conjunto de los Jueces Antonio Cançado Trindade y Alirio Abreu Burelli, párr. 2.

95 Vid. PANAMÁ. CSJ. PLENO. Sent. de 6 ene. 2009 (Acción de amparo, Gopu Mahboobani vs. Juez de Niñez y Adolescencia de la Provincia de Colón y la Comarca Kuna Yala). MP: Adán Arnulfo Arjona L., y Sent. de 10 mar. 2009 (Acción de amparo, El Rastro de Alessandría, S.A. vs. Tribunal Superior de Trabajo del Primer Distrito Judicial). MP: Adán Arnulfo Arjona L.

${ }^{96}$ Cf. WING SOLís, 2009. p. 108 y Curso de Derecho Ambiental, p. 53. 
Con respecto a la jerarquía de las normas contenidas en la Constitución, nos afiliamos al sector doctrinario que propugna la igualdad jerárquica de todas ellas. Nos referimos incluso a las normas programáticas [...]. Dichas disposiciones, a pesar de su índole, han de tener nominalmente la misma jerarquía normativa que los demás preceptos de la Constitución. ${ }^{97}$

\section{Justiciabilidad del derecho a un ambiente sano a nivel legal y reglamentario}

Durante la última década, profusa jurisprudencia ha reconocido el carácter justiciable del derecho a un ambiente sano en lo contenciosoadministrativo. Así, por ejemplo, haciendo uso de su potestad cautelar, ${ }^{98}$ la Sala Tercera ha suspendido un número plural de actos administrativos con base en consideraciones ambientales. Recientemente, se aplicó por primera vez el principio precautorio, ${ }^{99}$ al suspender provisionalmente una concesión para la extracción de arena continental en un área de manglar, ${ }^{100}$ y una resolución que regula la instalación de torres y antenas generadoras de emisiones radioeléctricas. ${ }^{101}$

Uno de los temas que mayor cantidad de litigios ambientales ha generado ha sido el de áreas protegidas, lo cual comprueba la constante presión de los intereses particulares antagónicos al bien común, a la cual nos hemos referido en trabajos anteriores (WING SOLÍS, 2002, p. 7-8).

97 QUINTERO CORREA, César A. "Método y Técnica de la Interpretación Constitucional," en ASOCIACIÓN PANAMEÑA DE DERECHO CONSTITUCIONAL (APADEC). Interpretación Constitucional. Panamá: Mizrachi \& Pujol, 1999, p. 43.

${ }^{98}$ Cf. PANAMÁ. ASAMBLEA NACIONAL. Ley n. 135 de 30 abr. 1943, "Orgánica de la Jurisdicción Contencioso-Administrativa” (G.0. 9,097 de 12 may. 1943), art. 73 y ss.

${ }^{99}$ Cf. Declaración de Río, Principio 15.

${ }^{100}$ Cf. PANAMÁ. CSJ. SALA TERCERA. Auto de 24 nov. 2008 (Acción de nulidad, Dora M. Villarreal, Elida G. de Aparicio y Otros contra una Concesión otorgada por el Ministerio de Comercio e Industrias (MICI)). MP: Adán Arnulfo Arjona L.

${ }^{101}$ Cf. PANAMÁ. CSJ. SALA TERCERA. Auto de 21 abr. 2009 (Acción de nulidad, Consejo Municipal de Panamá contra una Resolución de la Autoridad Nacional de los Servicios Públicos (ANSP)). MP: Adán Arnulfo Arjona L. 
Por ello, examinaremos algunos casos emblemáticos relacionados con este tema, para ilustrar la manera en que ha ido evolucionando la tutela judicial del derecho a un ambiente sano:

1) Corredor Norte. En este caso, se modificó la Ley que creó Parque Natural Metropolitano (PNM), "Pulmón de la Ciudad de Panamá", para permitir la construcción de esta carretera de peaje a través del mismo (1995). Una demanda de inconstitucionalidad fue negada porque los cargos estaban fundados en gran medida en el Régimen Ecológico y por estimarse infundado el cargo de violación a la irretroactividad de la Ley. ${ }^{102}$ Por otro lado, una acción de amparo contra la orden de proceder dictada por el Ministerio de Obras Públicas (MOP) no fue admitida por considerarse que el acto impugnado no revestía el carácter de orden de hacer. ${ }^{103}$ Finalmente, una acción de protección de DDHH tampoco fue admitida, por considerarse que la misma no podía impetrarse para tutelar derechos o intereses difusos. ${ }^{104}$ Sin embargo, la acción de nulidad presentada por la empresa PYCSA Panamá, S.A., concesionaria del Corredor Norte, contra la multa impuesta por el fenecido Instituto Nacional de Recursos Naturales Renovables (Inrenare), por el incumplimiento de las medidas de mitigación ambiental, fue fallada en contra, confirmando así dicha sanción pecuniária. ${ }^{105}$ Vale la pena mencionar que la empresa incumplió un contrato privado suscrito con el Patronato del PNM (persona jurídica de Derecho Privado), mediante el cual se había obligado a indemnizarlo por los daños ambientales causados. Por ello, el Patronato promovió un proceso civil ordinario de mayor cuantía,

\footnotetext{
${ }^{102}$ Supra, nota 127.

${ }^{103}$ Cf. PANAMÁ. CSJ. PLENO. Auto de 8 sep. 1995 (Acción de amparo, Sociedad Audubon de Panamá vs. MOP). MP: Mirtza Angélica Franceschi de Aguilera.

${ }^{104}$ Supra, nota 116.

${ }^{105}$ Cf. PANAMÁ. CSJ. SALA TERCERA. Sent. de 31 oct. 2000 (Acción de nulidad, PYCSA Panamá, S.A. contra una Resolución del INRENARE). MP: Mirtza Angélica Franceschi de Aguilera.
} 
el cual fue fallado a favor en primera y segunda instancia, estando pendiente de resolver el recurso de casación promovido por la empresa ante la Sala Primera de la CSJ. ${ }^{106}$

2) Camino Ecológico Boquete-Cerro Punta. En este caso, se modificó el Decreto que creó el Parque Nacional Volcán Barú (PNVB) en la Provincia de Chiriquí, para permitir que dicha carretera lo atravesara (2003). Una acción de nulidad, promovida por uno de los Fiscales Ambientales del Ministerio Público contra las autorizaciones administrativas y el contrato de obra pública, fue inicialmente inadmitida por supuesta falta de legitimación activa, ${ }^{107}$ pero luego admitida al resolverse la apelación contra dicha decisión, ${ }^{108}$ y finalmente resuelta en forma favorable, declarándose ilegales los actos demandados, por ser incompatibles con los fines de conservación del PNVB. ${ }^{109}$ Posteriormente se declaró sustracción de materia sobre otra acción similar contra el cambio reglamentario, promovida por Ancon y el Defensor del Pueblo. ${ }^{110}$

3) Proyecto Minero Cerro Petaquilla. Se trata de una mina de oro a cielo abierto cuyos graves impactos ambientales sobre el Parque Nacional Omar Torrijos Herrera (El Copé) y las comunidades aledañas han trascendido a la opinión pública (2005). Una advertencia de ilegalidad contra el reglamento de EIA fue negada con fundamento en que el contrato ley entre el Estado y la empresa (1997) no tiene jerarquía legal, y por consiguiente no exime a la empresa de cumplir con la normativa erga omnes de protección ambiental. ${ }^{111}$

\footnotetext{
${ }^{106}$ Vid. PANAMÁ. CSJ. SALA PRIMERA. Auto de 16 mar. 2009 (Recurso de casación, PYCSA Panamá, S.A. vs. Patronato del Parque Natural Metropolitano). MP: Alberto Cigarruista Cortéz.

${ }^{107}$ Cf. PANAMÁ. CSJ. SALA TERCERA. Auto de 22 feb. 2003 (Supra, nota 125). MP: Winston Spadafora F. ${ }^{108}$ Supra, nota 125.

${ }^{109}$ Cf. PANAMÁ. CSJ. SALA TERCERA. Sent. de 9 feb. 2006 (Supra, nota 125). MP: Winston Spadafora F. ${ }^{110}$ Cf. PANAMÁ. CSJ. SALA TERCERA. Auto de 19 ago. 2005 (Acción de nulidad, ANCON y Defensor del Pueblo contra el Decreto Ejecutivo n. 107 de 13 nov. 2003). MP: Jacinto A. Cárdenas M.

${ }^{111}$ Cf. PANAMÁ. CSJ. SALA TERCERA. Sent. de 29 jul. 2008 (Advertencia de ilegalidad contra el D.E. 209 de 2006, Petaquilla Gold, S.A. vs. ANAM). MP: Adán Arnulfo Arjona L.
} 
4) Proyecto Red Frog Beach Club (Fase 2). Se trata de un proyecto hotelero turístico adyacente al Parque Nacional Marino Isla Bastimentos en la Provincia de Bocas del Toro, cuyo EIA fue aprobado por la Anam (2007) a pesar de la fragilidad del área protegida y de los conceptos técnicos adversos emitidos por varias UAS. Una acción de nulidad contra la resolución aprobatoria de dicho EIA fue fallada favorablemente, por violaciones a la normativa de protección ambiental legal y reglamentaria, así como a cuatro tratados internacionales ambientales. ${ }^{112}$

La forma en que han evolucionado los anteriores casos emblemáticos ilustra claramente cómo el alto grado de protección actual, derivado del profuso desarrollo legal y reglamentario expuesto anteriormente, hace cada vez más insostenible seguir calificando al Régimen Ecológico de la Constitución como programático.

\section{Conclusión}

Tal vez sin estar del todo consciente de ello, el Estado panameño ha hecho ingentes esfuerzos por llevar a la práctica los estándares interamericanos de DDHH en materia de Desc, y concretamente en lo que se refiere al derecho a un ambiente sano. Sin embargo, todavía queda mucho por hacer. Lo importante es que todos los operadores del sistema continúen internalizando, profundizando y ampliando a todos los niveles, a través de sus actuaciones y decisiones, los parámetros propuestos. Esperamos que este trabajo contribuya de algún modo al logro de este objetivo.

${ }^{112}$ Cf. PANAMÁ. CSJ. SALA TERCERA. Sent. de 27 nov. 2008 (Acción de nulidad, Rutilo Milton Beker \& Delfino Hooker Midi contra una Resolución de la ANAM). MP: Winston Spadafora F. 


\section{Referencias}

ALLOTT, P. International law and international revolution: reconceiving the world. In: HUNTER, D.; SALZMAN, J.; ZAELKE, D. International environmental law and policy. 2nd ed. New York: Foundation Press, 2002. p. 1486.

ASOCIACIÓN INTERAMERICANA PARA LA DEFENSA DEL AMBIENTE AIDA. Guía de defensa ambiental: construyendo la estrategia para el litigio de casos ante el sistema interamericano de derechos humanos. México: AIDA, 2008.

BORRERO NAVIA, J. M. Protección penal de los derechos ambientales: de la criminología al derecho penal ecológico. Cali: Fundación para la Investigación y Protección del Medio Ambiente (FIPMA), 1990. p. 51.

CAVALLARO, J. L.; SCHAFFER, E. J. Less as more: rethinking supranational litigation of economic and social rights in the americas. 56 Hastings L. J. 217 (2005), In: MELISH, T. J. Rethinking the "Less as More" Thesis: supranational litigation of economic and social rights in the Americas. 39 N.Y.U. J. Int'l L. \& Pol. 171 (2006), p. 196.

COATES, A. Panamá cambió el planeta. Revista Ellas, Panamá, n. 998, 2009.

COLOMER VIADEL, A. Constitución, Estado y Democracia en el siglo XXI. Valencia: Universidad Politécnica de Valencia, 2006.

ENCYCLOPÆDIA BRITANNICA. Human rights. Encyclopædia Britannica Online. 2009. Traducción libre. Disponible en: 〈http://www.britannica.com〉. Consultado el: 20 ago. 2009a.

ENCYCLOPÆDIA BRITANNICA. Isthmus of Panama. Encyclopædia Britannica Online, Chicago, 2009b.

FRÍAS, Y. Cuatro problemas de la teoría kelseniana sobre el derecho internacional. Boletín Mexicano de Derecho Comparado, Año XIX, n. 55, p. 67-68, enero/abr. 1986. 
GARCÍA RAMÍREZ, S. Protección jurisdiccional internacional de los derechos económicos, sociales y culturales. In: CENTRO POR LA JUSTICIA Y EL DERECHO INTERNACIONAL - CEJIL. Construyendo una agenda para la justiciabilidad de los derechos económicos, sociales y culturales. San José, Costa Rica: Centro por la Justicia y el Desarrollo Internacional, 2004.

GARCÍA-SAYÁN, D. Una viva interacción: Corte Interamericana y Tribunales Internos. In: VARIOS. La Corte Interamericana de Derechos Humanos. Un cuarto de siglo: 1979-2004. San José, Costa Rica: Corte Interamericana de Derechos Humanos, 2005. p. 326.

HECKADON-MORENO, S. (Ed.). Panamá, puente biológico. Panamá: Instituto Smithsonian de Investigaciones Tropicales, 2001.

IBARGÜEN BURGOS, G. M. Derecho internacional, derecho internacional de los derechos humanos y Tribunal Constitucional. Revista IIDH, v. 38, p. 33, jul./dic. 2003.

KELSEN, H. Principios de derecho internacional. Buenos Aires: El Ateneo, 1952.

LÓPEZ ZAMARRIPA, N. Régimen legal internacional en torno al patrimonio común de la humanidad. Derecho y Cultura, n. 4, p. 122, 2001.

MELISH, T. J. Rethinking the "Less as More" Thesis: supranational litigation of economic and social rights in the Americas. 39 N.Y.U. J. Int'l L. \& Pol. 171 (2006), p. 196.

MORENO CRUZ, R. El modelo de Luigi Ferrajoli: lineamientos generales. Boletín Mexicano de Derecho Comparado, Año XL, n. 120, p. 825-852, sept./ dic. 2007. (Nueva Serie).

ORELLANA, M. A. Derechos humanos y ambiente: desafíos para el sistema interamericano de derechos humanos. Ozono Mio Revista de Derecho Ambiental, año 1, n. 6, p. 291, 2008.

PIZARRO SOTOMAYOR, A.; MÉNDEZ POWELL, F. Manual de derecho internacional de derechos humanos - aspectos sustantivos. Panamá: Universal Books, 2006. 
UNESCO. World water development report: water in a changing world. 3 . ed. París: 2009. p. 18.

UPRIMNY YEPES, R.; UPRIMNY YEPES, M.; PARRA VERA, O. Derechos humanos y derecho internacional humanitario, módulo de autoformación, Escuela Judicial “Rodrigo Lara Bonilla”. Bogotá: Consejo Superior de la Judicatura, 2006. VEGA REYES, V. El Título Constitucional sobre el Canal. In: VARIOS. El Canal de Panamá. Panamá: Editorial Universitaria Carlos Manuel Gasteazoro, 1999. (Biblioteca de la Cultura Panameña).

VENTURA ROBLES, M. E. Jurisprudencia de la Corte Interamericana de derechos humanos en materia de derechos económicos, sociales y culturales. Revista IIDH, v. 40, p. 87-132, jul./dic. 2004.

WING SOLÍS, F. Derecho, ambiente y desarrollo: el caso de los rellenos sobre la Bahía de Panamá. 2002. Tesis - Universidad de Panamá, Panamá, 2002.

Recibido: 29/09/2009

Recebido: 29/09/2009

Aprobado: 02/11/2009

Aprovado: 02/11/2009 